\title{
Quality of life measurement for patients with diseases of the airways
}

\author{
P W Jones
}

Treatment for diseases of the airways is largely palliative, being directed in the main towards the reduction of acute exacerbations and limitation of the impact of disease on daily life. For the purposes of measurement, the latter may be regarded as a series of different activities, some of which are listed in the right hand box of figure 1. Disturbance of these activities may result from a range of pathophysiological disorders, which mediate their effects through a limited number of symptoms. Despite the palliative nature of treatment for airways disease, relatively little regard has been paid to the activities listed in the right hand box of figure 1 as possible measures of therapeutic outcome. It is generally assumed that a measured improvement in the disease processes shown on the left of figure 1 will be accompanied by improved health and wellbeing. This assumption is based on the belief that the arrows in this figure imply a direction of causality that holds both during the development of a disease and with the response to treatment. In fact, there is surprisingly little scientific evidence that treatment improves the overall state of patients with a chronic disease. Before we consider treatment, the processes by which disease activity in the lungs leads to the disruption of daily living are worth examining. The disturbances in physiological function listed in the left hand box of figure 1 are well documented. There is also a growing body of literature describing measured disturbances of the activities listed in the right hand box. But how are these disturbances linked and what are the quantitative relationships between them?

To illustrate this problem, it is worth looking more closely at the effects of breathlessness. Figure 1 suggest a simple linear sequence, but the scheme in figure 2 is more realistic. This model is not complete, and I make no claim that it provides profound insights; but there is experimental evidence for most of the links between the boxes, and other links are reasonable hypotheses based on current knowledge. The pathway is not tidy; some arrows linking two boxes are bidirectional and some paths form loops. The loops are important because they allow positive feedback, which then enables the system to become autonomous. Even if the precipitating event were entirely corrected, the resulting disturbances would persist and only decay at a rate fixed by the time constants of the system's individual components. An obvious example is the muscle wasting that results from reduced physical activity. In a study of 152 patients with airways obstruction who performed a 10 minute paced step test, 45 stopped because of breathlessness, whereas 73 stopped because of factors such as fatigue and weak legs (C M Baveystock, P W Jones, unpublished observations). Some pathways illustrated in figure 2 may even be irreversible-loss of employment, for example. The scheme in figure 2 is presented hierarchically. At each level additional factors are fed in and interact with signals coming up from below. These factors may be unrelated to the basic disease, yet may modulate the signal produced by the underlying pathological process quite profoundly. Without knowledge of the operating characteristics of the individual processes and information on the size of the outside influences, we could not predict the magnitude of the disturbances at the top of this system from a knowledge of a disturbance at the bottom, no matter how accurately it was measured.

\section{Breathlessness: the link between lung disease and disability}

Quality of life measurement is concerned with the events at the top of figure 2 , but some intermediate steps must be considered. Breathlessness is the critical link between lung disease and ensuing disability, yet the factors that determine it are poorly understood. Studies during standardised ergometer exercise tests in normal subjects have shown wide variations between individuals in the intensity of perceived dyspnoea in relation to ventilation. ${ }^{1-3}$ The reasons for this diversity are still unknown. There is also evidence that the level of distress that normal subjects associate with their breathlessness during exercise is unrelated to their perception of its intensity. ${ }^{4}$ Comparable studies in patients have not been performed and we do not know which aspects of breathlessness limit daily activity. The generation of breathlessness is a critical process in the production of impaired exercise tolerance, but currently we can neither predict an individual patient's level of breathlessness nor quantify the effect of changes in lung function on it.

\section{Spirometry, exercise tolerance, and disability}

In patients with obstructive airways disease the correlation between the results of spirometry and walking distance are poor. ${ }^{56}$ Even with 
Figure 1 List of disease processes, symptoms, and activities that may be disturbed by chronic diseases of the airways. Note that spiritual activity is bracketed, because unlike the other listed types of activity, it does not have reliable methods of measurement.

\begin{tabular}{|c|c|c|}
\hline PATHOPHYSIOLOGY & SYMPTOMS & ACTIVITIES \\
\hline $\begin{array}{l}\text { Mucus hypersecreation } \\
\text { Airway obstruction } \\
\text { Lung overinflation } \\
\text { Compliance changes } \\
\dot{\text { V} / Q ் ~ m i s m a t c h ~} \\
\text { Pulmonary hypertension }\end{array}$ & $\begin{array}{l}\text { Cough } \\
\text { Sputum } \\
\text { Wheeze } \\
\text { Breathlessness }\end{array}$ & $\begin{array}{l}\text { Physical } \\
\text { Social } \\
\text { Emotional } \\
\text { Intellectual } \\
\text { Economic } \\
\text { (Spiritual) }\end{array}$ \\
\hline
\end{tabular}

Right ventricular failure Polycythaemia

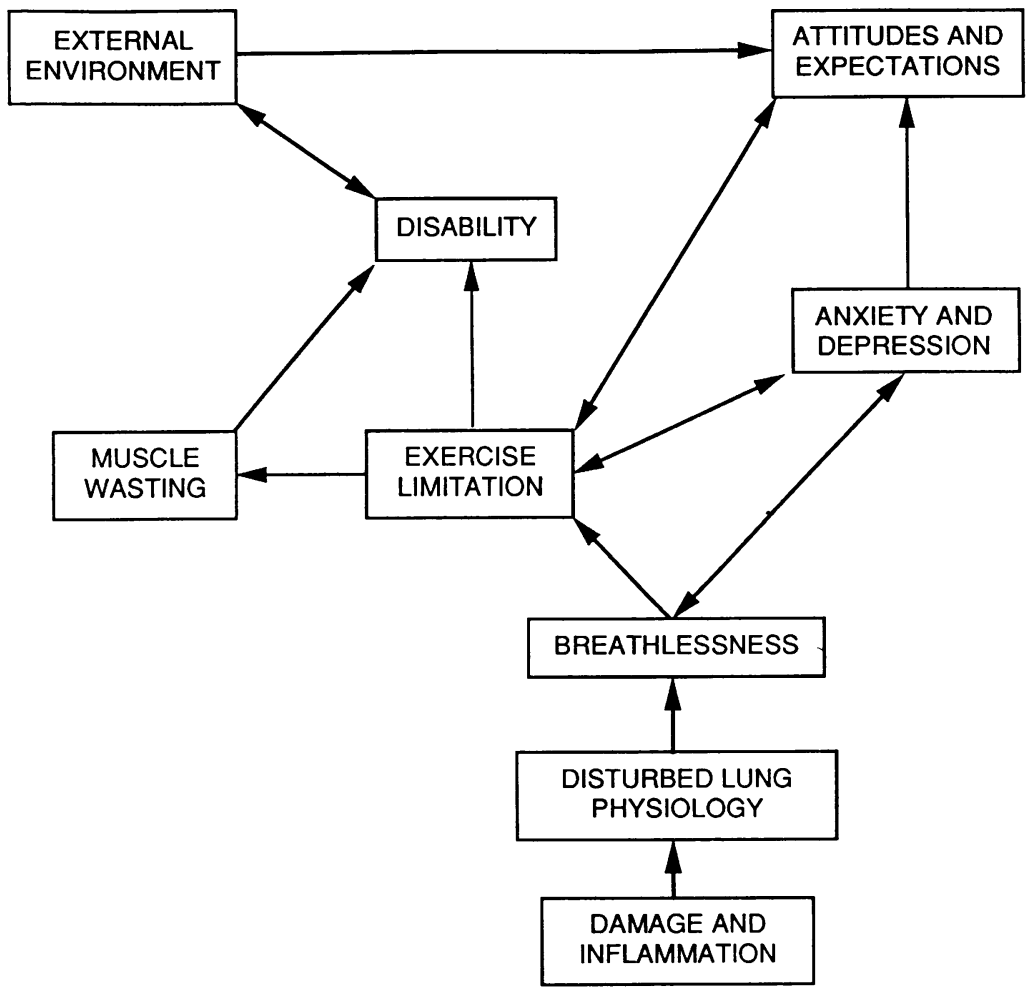

Figure 2 Pathways linking disturbances arising in the lungs to factors that may affect patients' quality of life. tion of breathlessness is a more important factor than airflow limitation in determining the impact of lung disease on patients' exercise tolerance and disability. Support for this conclusion comes from a study of asthmatic patients. Those patients who showed the lowest level of breathlessness in relation to their ventilation during cycle ergometer exercise also had the best walking distance performance. This association could not be explained by the severity or variability of the patients' asthma. ${ }^{16}$ In summary, there is clear evidence that walking distance and subjective disability are well correlated and probably quite closely linked. In contrast, links between the pathophysiological processes measured by spirometry and the patients' breathlessness, physiological impairment, and disability appear to be tenuous. We may predict therefore that subjectively perceived impairment of health is likely to correlate poorly with spirometric measurements of airway function.

\section{General health questionnaires}

Disturbance to health may be viewed as a series of impacts on daily life and wellbeing. Measurement of health related quality of life can therefore be defined as "quantification of the impact of disease on a patient's life and perceived wellbeing in a formal and standardised manner" (the italics emphasise my own prejudice). The most comprehensive

symptom limited ergometer stress tests, the maximum achievable exercise ventilation cannot be reliably predicted from $\mathrm{FEV}_{1} \cdot{ }^{78}$ Formal exercise tests provide an estimate of patients' physiological impairment. Disability is a more subjective measure, concerned with the manner in which daily activity is restricted by physiological impairment. Measures of disability are usually relatively short and simple questionnaires or scales. The best known example in chest medicine is the Medical Research Council (MRC) dyspnoea scale, ${ }^{9}$ but others used in obstructive airways disease include the oxygen cost diagram ${ }^{10}$; the Borg ratio of perceived exertion ${ }^{11}$; and the Mahler dyspnoea index. ${ }^{12}$ The results of spirometry have been shown to correlate relatively poorly with such measures, ${ }^{11-14}$ whereas walking distance correlates quite well. ${ }^{10-1215}$ These observations are interesting and important. The most plausible explanation is that variability between individuals in the percepmeasurements of quality of life currently available are provided by general health questionnaires such as the Quality of Wellbeing Scale $^{17}$ and the Sickness Impact Profile. ${ }^{18}$ Detailed reviews are available elsewhere. ${ }^{19} 20$ These questionnaires were developed to express, in numerical terms, disturbances to health as seen from the patient's viewpoint. They were the result of painstaking research directed towards the development of methods by which a large proportion of the spectrum of human $d y s$-ease could be quantified in the most economical way (that is, by compressing the maximum amount of information into the smallest number of terms). There was, of course, no "gold standard" against which the questionnaires could be judged, so during their development extensive tests of validity were carried out. These concentrated on content, structure, internal reliability, and repeatability. The methods have been described in detail 
elsewhere. ${ }^{19-21}$ Although these questionnaires could not be compared with a reference "gold standard", three important measures of general health, each developed from a different theoretical base and with a different structure, have been compared in a comprehensive study and moderately good correlations were found between them. ${ }^{22}$

\section{General health questionnaires in airways disease}

The Quality of Wellbeing Scale ${ }^{17}$ and the Sickness Impact Profile ${ }^{23-28}$ have been used in patients with airways disease. Their scores have been shown to correlate with several relevant indices of disease activity, disability, and distress ${ }^{1725-29}$ and their ability to distinguish between different levels of disease activity has been clearly shown. For example, in patients whose breathing never returned to normal between attacks of breathlessness and wheeze quality of life measured in terms of the Sickness Impact Profile score was considerably worse than in patients who did have symptom free periods. ${ }^{25}$ Spirometric measures in general have been correlated relatively poorly with general health indices such as the Quality of Wellbeing Scale ${ }^{17}$ and the Sickness Impact Profile. ${ }^{25-27}$ In contrast, the six minute walking distance has been shown to account for $40 \%$ of the variance in the Sickness Impact Profile score. ${ }^{25}$ This score has also been shown to correlate quite well with disability as assessed by the MRC dyspnoea scale ${ }^{25} 26$ and the oxygen cost diagram. ${ }^{26}$ Nevertheless, although these correlations were statistically significant, they were too low for general health to be accurately predicted from simple measurements of disability. This overall picture is rather similar to the pattern of correlations observed between spirometric measurements, walking distance, and disability.

The Sickness Impact Profile was designed for application to a very wide range of diseases, and inevitably its content provides restricted coverage of any particular clinical condition. This may limit its precision and result in low sensitivity. For example, in patients with chronic obstructive airways disease, Sickness Impact Profile scores did not differ in patients with the two mildest grades of disability on the MRC dyspnoea scale, but did show progressive differences between the three higher grades. ${ }^{25}$ There also appears to be a non-linear relation between disease severity, as measured by prebronchodilator $\mathrm{FEV}_{1}$ and Sickness Impact Profile score ${ }^{23-28}$ (summarised in fig 3). In studies in which the mean $\mathrm{FEV}_{1}$ was less than $50 \%$ predicted there was a progressive worsening in the score by comparison with studies in which the mean $\mathrm{FEV}_{1}$ was above this level. This relative insensitivity for mild to moderate disease could mean that the questionnaire is more responsive to deterioration than to improvement. This may be critically important for attempts to measure the response to treatment.

\section{Advantages of standardised health questionnaires}

General health measures such as the Sickness Impact Profile and Quality of Wellbeing Scale are standardised. Each patient completes exactly the same questionnaire, which is always scored in the same way. Both of these questionnaires produce a single index or summary score, and with the Sickness Impact Profile a profile of category scores may also be calculated to provide a more detailed description of the disturbances of daily life. Such profiles for patients with different levels of airflow limitation have been published. ${ }^{252729}$ The advantage of standardised health scores is that they allow comparisons not only between subjects within a given study but across study populations, as shown in figure 3. Furthermore, if a standardised questionnaire were sufficiently sensitive, its score would allow direct comparisons of efficacy between therapeutic trials. Some of the solutions to the problem of designing a sensitive questionnaire have overlooked this property. Examples include some otherwise good and successful measures. One of these is the Mahler transition score for breathlessness, ${ }^{12}$ which measures one symptom only, though an important and disabling one. Therapeutic benefit from theophylline ${ }^{30}$ and targeted muscle training ${ }^{31}$ has been demonstrated with this measure. As its name suggests, this measure grades changes in symptoms with respect to each patient's baseline state, so it allows only semiquantitative comparisons between responses from different patients or studies. The first quality of life measure developed specifically for chronic airflow limitation, the Chronic Respiratory Questionnaire, ${ }^{32}$ is also not completely standardised. It has the worthy property of allowing patients partially to tailor the questionnaire to suit their state, but unfortunately this "individualisation" does not allow a standardised score to be calculated. Use of this measure has shown quality of life benefits of bronchodilators, ${ }^{33}$ but direct comparisons of efficacy between this and other studies in which the same questionnaire may be used will not be possible. This problem has been exemplified recently in a study using the chronic respiratory questionnaire to compare patients with chronic obstructive airways disease and cystic fibrosis. In that study the authors had to adjust the scores from the patients with cystic fibrosis to allow comparisons with the patients with chronic obstructive airways disease because the former identified fewer areas of daily life causing dyspnoea. ${ }^{34}$

Disease specific measures of quality of life There is a need for a standardised and sensitive measure of the impact of chronic airways diseases on the daily life and perceived wellbeing of patients with these conditions. As discussed previously, comprehensive coverage of many different diseases may render the measure too insensitive for specific disease states. Sensitivity may be increased by limiting 
Figure 3 Mean values for pre-bronchodilator FEV , and Sickness Impact Profile (SIP) scores from published studies. The number in each box is the number of the study given in the reference list, with the exception of * which is currently unpublished (Quirk FH, Jones PW). The patients in references 23-25 had chronic obstructive airways disease. In reference 26 chronic obstructive airways disease and asthma were combined. The patients in reference 28 had "non-specific" airways obstruction. The remaining two studies were on patients with asthma. The total number of patients in these studies exceeds 1800.

Note that the psychosocial and physical scores are subscores of the Sickness Impact Profile, with selfexplanatory titles.

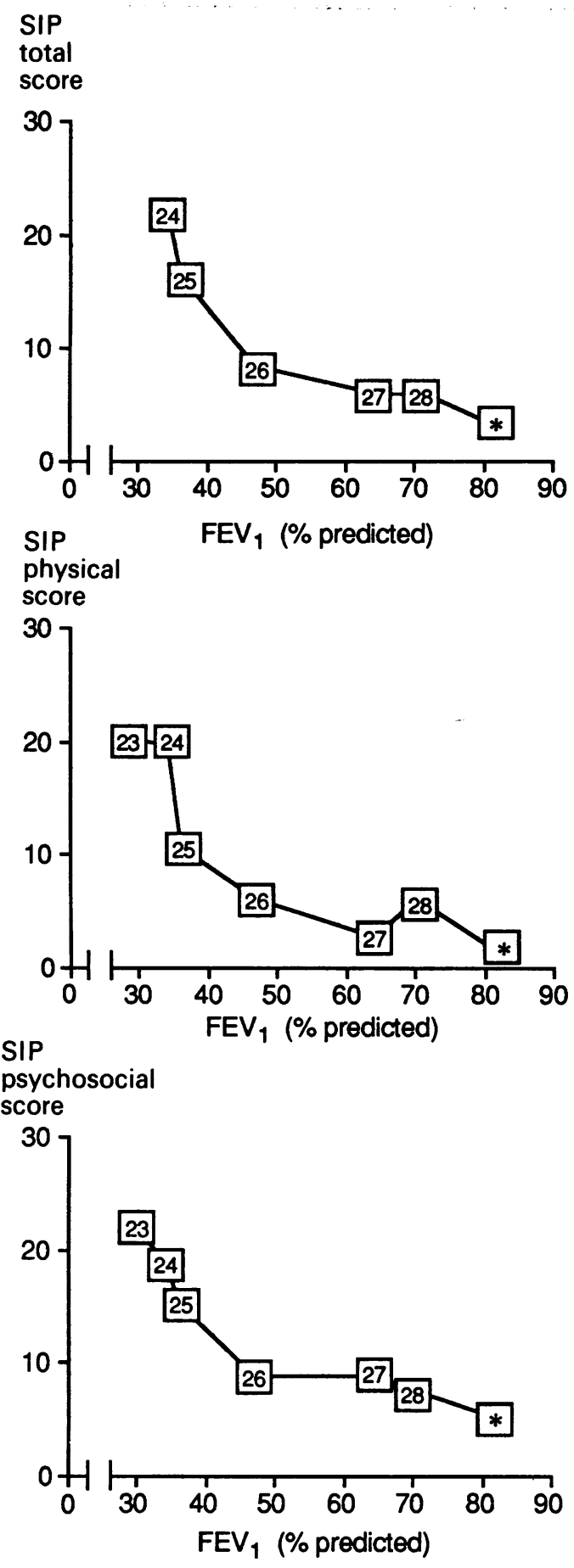

the questionnaire's content to items selected to reflect a broad range of effects of a specific disease or a limited group of related diseases. This restriction of the questionnaire's content has occasionally led to the criticism that a disease specific measure is something less than a "true" quality of life measure as it addresses a limited area of disturbance to health. Such criticism may be based on a narrow understanding of the varied and complex nature of any single disease. General health measures are a best attempt to cover the whole spectrum of $d y s-$ ease, but this inevitably reduces the number of items referable to a specific clinical condition. For example, the Sickness Impact Profile includes items concerned with intravenous feeding, but has a few items that are relevant to patients with airways disease. In a study of 152 patients with moderately severe chronic obstructive airways disease $20 \%$ of the items in this questionnaire were left completely unanswered by every patient, and a quarter of the questionnaire items accounted for two thirds of the total number of positive responses ( $P$ W Jones, C M Baveystock, unpublished observations). The overall effect of this is to produce very low scores even in patients who have moderate levels of disability. ${ }^{25}$ A correctly designed and appropriately applied disease specific questionnaire might therefore provide a better and more precise measurement of quality of life than a general index.

\section{The St George's respiratory questionnaire}

We have developed a measure of impaired health in patients with diseases causing airway obstruction, both asthma and chronic obstructive airways disease, known as the St George's respiratory questionnaire. This questionnaire is divided into three components: symptoms, activity, and impacts. A total score is also calculated. The "impacts" section covers social and emotional disturbances due to the disease. Although some items in this section relate to the psychological impact of the disease, questions designed specifically to measure anxiety and depression were excluded as several suitable questionnaires are available for this purpose. Each item in the St George's respiratory questionnaire is accorded a weight for the amount of distress associated with the symptom or state described. These weights were obtained during the questionnaire's development from studies in 140 asthmatic patients in six countries. Factors such as age, sex, and the duration, severity, and variability of disease each contributed to less than $2 \%$ of the variance in weights between patients. ${ }^{35}$ There was no significant difference in the weights obtained in England, Finland, Italy, Thailand, or the United States ${ }^{36}$; but the weights from the Netherlands were on average $19 \%$ higher than those obtained in the other countries. No obvious explanation was found for this exception. The weights in asthmatic patients were almost identical to weights collected in a group of older patients with chronic obstructive airways disease who had more severe disease. ${ }^{37}$ As a result of these studies, we have concluded that the weights are suitable for a wide range of patients with airways disease.

The final version of the questionnaire has good repeatability for this type of measure. ${ }^{37}$ To assess its reliability-that is, its ability to distinguish between different levels of healththe questionnaire was compared with other measures of disease severity, disability, and distress, including spirometric measurements, bronchodilator response, results of oximetry during exercise, six minute walking distance, the MRC respiratory questionnaire, the hospital anxiety and depression scale, ${ }^{38}$ and the Sickness Impact Profile, in a study on large numbers of patients with a wide spectrum of airflow obstruction. ${ }^{37}$ The component parts of 
the questionnaire correlated with appropriate reference measures and the total score was shown to sum a range of different disturbances to health. The pattern of correlations between the St George's respiratory questionnaire scores and the reference variables closely followed the pattern obtained with the Sickness Impact Profile, but the St George's questionnaire was over twice as sensitive to differences in disease severity as the Sickness Impact Profile. ${ }^{39}$ Measurements performed one year apart showed that changes in the St George's respiratory questionnaire scores correlated with changes in the reference measures listed above and showed that the total score aggregated changes in several different areas of disease activity. ${ }^{37}$

\section{Mood state in patients with diseases of the airways}

A high incidence of clinically important psychological morbidity, as measured by the general health questionnaire, has been reported in patients with chronic obstructive airways disease. ${ }^{264041}$ In one study of patients with a mean post-bronchodilator $\mathrm{FEV}_{1}$ of $53 \%$ predicted $47 \%$ of the patients had an anxiety score at or above the borderline of clinical significance on the hospital anxiety and depression scale and $29 \%$ had depression scores in this range. ${ }^{25} \mathrm{~A}$ further study recorded moderate levels of anxiety on the basis of the Speilberger index, and borderline levels of depression according to the Beck depression inventory. ${ }^{42}$ In younger asthmatic patients anxiety levels have been reported to be higher than in normal subjects. ${ }^{43} \mathrm{~A}$ correlation between psychological morbidity and poor spirometric results has been found in patients with chronic obstructive airways disease ${ }^{32}$ and psychological state may influence patients' reporting of respiratory symptoms. ${ }^{26}$ The latter has important implications for quality of life measurement. Anxiety and depression scores were found to correlate with the symptoms score from the St George's respiratory questionnaire. To analyse this further, responses to the MRC respiratory questionnaire items about the frequency of cough and wheeze were included with the anxiety or depression score in a multivariate statistical model. ${ }^{37}$ In this model, in which the St George's symptoms score was the dependent variable, respiratory symptoms were the dominant correlates and correlations with mood scores were much weaker. A similar picture was seen with the St George's activity score. Correlations with anxiety and depression were found with this score, but these correlations became weaker when the MRC dyspnoea score was included in a multivariate model and the dyspnoea score then became the dominant correlate. In contrast, correlations between mood score and the impacts score of the St George's questionnaire remained strong, even in multivariate models that included other powerful correlates of the impact score, such as responses to MRC questionnaire items concerned with dyspnoea and frequency of wheeze. Mood state scores appear therefore to correlate with the symptoms and activity sections of the St George's questionnaire, largely through a shared association with measures of disease activity, including symptom severity, physical impairment, and perceived disability. The impacts section contains items that correlate with anxiety independently of other disease related factors. Clearly relations between anxiety, depression, and the perception of health are complex and still poorly delineated.

\section{Quality of life questionnaires in clinical trials}

"Quality of life" measures are now beginning to appear in clinical trials, but are they anything more than a marketing ploy? I believe that they are. Most people would agree, that with a lifelong disease, a major requirement of any therapy should be a clear demonstration of its beneficial effects on daily life and wellbeing. As discussed earlier, it is not possible to make reliable predictions of a patient's disability or impaired wellbeing from measurements of airways function. There is as yet, limited data concerning the relationship between changes in spirometry following therapy and changes in health, but the available evidence suggests a generally poor correlation. In patients with asthma studied over an eighteen month interval, changes in $\mathrm{FEV}_{1}$ correlated with changes in quality of life measured with the quality of wellbeing scale $\left(r^{2}=0.40\right) .{ }^{17}$ In a study of bronchodilators in patients with chronic obstructive airways disease there was a significant correlation $\left(\mathrm{r}^{2}=0.30\right)$ between $\mathrm{FEV}_{1}$ and quality of life as determined by the chronic respiratory questionnaire. ${ }^{44}$ In both of these studies the correlations, though moderately good, were too low to allow accurate prediction of the quality of life score from the $\mathrm{FEV}_{1}$. In another study in patients with chronic obstructive airways disease over a one year interval changes in quality of life as assessed by the St George's respiratory questionnaire score correlated poorly with change in FEV, but rather better with the patient's walking distance or the MRC dyspnoea score. ${ }^{37}$ A study on the effect of salbutamol in chronic obstructive airways disease found a very low and non-significant correlation between changes in spirometric values and perceived breathlessness. ${ }^{13}$ Finally, in a study using theophylline, breathlessness improved but with no significant change in spirometric results, arterial blood gas tensions, or walking distance. ${ }^{30}$ Clearly we cannot assume that improvement in subjective health or disability will accompany a measured improvement in airways function.

Health questionnaires were developed as a scientific response to the problem of quantifying aspects of disease severity that could not be assessed by existing measures. Properly developed health related quality of life questionnaires are validated measures of the impact of a disease on the patient's daily life and perceived wellbeing. In tests of drug efficacy it is clearly appropriate to measure the drug's 
effect on the patient's health and not just spirometric values. The use of standardised measurements will allow direct comparisons of efficacy, measured in terms of overall effects on daily life and wellbeing, between different trials, drugs, and therapeutic modalities. Only the accumulation of a large body of studies will allow a judgment about whether spirometry can provide an adequate surrogate measure of improvement in health (as opposed to airways function).

\section{Quality of life measures in audit and routine practice}

Quality of life measures are clearly suitable for auditing the outcome of medical care in terms of patients' perceived health, but they should not be confused with measures of "satisfaction". 45 Measurement of satisfaction is a process used to assess the success with which the supplier or a process meets or exceeds the requirements of a consumer or client. It has to be scored largely in relative terms. A discussion of the intriguing and complex relations between satisfaction and perceived health and wellbeing is beyond the remit of this review. It should be realised, however, that in the context of medical audit there may be significant differences between the conclusions obtained from an audit using a quality of life measure and one using a satisfaction index. Consider these two statements: "In this audit $80 \%$ of patients were satisfied with their improvement with treatment" and "In this audit the mean baseline health score of the patients was 40 units; $60 \%$ of patients achieved or surpassed the minimum criterion for improvement." The first statement says nothing about the patients' health, gives no indication of which aspect of their treatment satisfied them, and provides no measure of the size of any improvement. The second gives a clear statement about the baseline state of health of the patients and the proportion who improved by a predetermined amount, though it does not state what proportion felt satisfied with this level of improvement.

The role of quality of life measures in routine clinical practice has yet to be established. The St George's respiratory questionnaire, for example, takes about 10 minutes to completea little less than the time taken to test bronchodilator responsiveness. We are investigating its application to routine practice and are examining the possibility of developing shortened versions. One problem may arise because quality of life measures may not be quite as repeatable as spirometry. This may limit their routine use for testing therapeutic responses in individuals as opposed to groups of patients. Despite this qualification I believe that, either in its current form or in shortened forms, quality of life questionnaires will provide valuable information for routine clinical management and that they will complement but not replace physiological measurement.

\section{Limitations of quality of life measures in} airways disease

Questionnaires for quality of life measurement should be applied only to diseases in which their use has first been validated. Even when appropriately selected the presence of intercurrent disease could be a confounding factor. Unreliable results may be produced if quality of life measures are used incorrectly. In general, these questionnaires are easy to use and fairly robust, but they should be handled with the same care and attention to detail as any other instrument. One perceived limitation may be the rate of change with treatment. By comparison with measurement of disturbances close to the underlying pathological process (as illustrated in figs 1 and 2) quality of life scores may respond to therapeutic intervention quite slowly. This is not due to an inherent weakness in the questionnaires but is a reflection of the influence of factors that can modulate the impact of disease on the patient's life. Many of these factors may be unrelated to the underlying disease process and therefore would not be directly influenced by treatment. Disuse atrophy of leg muscles due to exercise limitation resulting from breathlessness is an obvious example. Instant cure would not immediately return the patient's life to its premorbid state. Finally, expectations of quality of life measurement should be realistic. If a treatment has little measurable influence on the underlying disease processes or on processes close to it, it is unlikely to improve subjectively perceived wellbeing unless it also possesses direct pyschoactive properties, as may be the case with oral corticosteroids. ${ }^{42}$ Good quality of life measures are well validated instruments that provide hard data on health. They are not magic wands to be used when other measurements have shown little benefit from the treatment under study.

1 Stark RD, Gambles SA, Lewis JA. Methods to assess breathlessness in healthy subjects: a critical evaluation and application to analyse the acute effects of diazepam and promethazine on breathlessness induced by exercise or by promethazine 1981;61:429-39.

2 Adams L, Chronos N, Lane R, Guz A. The measurement of breathlessness induced in normal individuals: individual differences. Clin Sci 1986;70:131-40.

3 Wilson RC, Jones PW. A comparison of the visual analogue scale and modified borg scale for the measurement of dyspnoea during exercise. Clin Sci 1989;76:277-82.

4 Wilson RC, Jones PW. Differentiation between the intensity of breathlessness and the distress it evokes in normal subjects during exercise. Clin Sci 1991;80:65-70.

5 McGavin CR, Gupta SP, McHardy GJR. Twelve minute walking test for assessing disability in chronic bronchitis. BMJ 1976;i:822-3.

6 Swinburn CR, Wakefield JM, Jones PW. Performance, ventilation and oxygen consumption in three different types of exercise test in patients with chronic obstructive lung disease. Thorax 1985;40:581-6.

7 Carter R, Peavler M, Zinkgraf S, Williams MS, Fields S. Predicting maximal exercise ventilation in patients with chronic obstructive pulmonary disease. Chest 1987; 92:252-9.

8 Matthews JL, Bush BA, Ewald FW. Exercise responses during incremental and high intensity and low intensity steady state exercise in patients with obstructive lung steady state exercise in patients with obstructive lung
disease and normal control subjects. Chest 1989;96:11-7. disease and normal control subjects. Chest 1989;96:11-7.
Medical Research Council Committee on the Aetiology of Chronic Bronchitis. Standardised questionnaire on respiratory symptoms. $B M J 1960$;ii: 1665.

10 McGavin CR, Artvinli M, Naoe H, McHardy GJR. Dyspnoea, disability and distance walked: comparison of 
estimates of exercise performance in respiratory disease. $B M J$ 1978;ii:241-3.

11 O'Reilly JF, Shaylor JM, Fromings KM, Harrison BDW. The use of the 12 minute walking test in assessing the effect of oral steroid therapy in patients with chronic airways obstruction. Br J Dis Chest 1982;76:374-82.

12 Mahler DA, Weinberg DH, Wells CK, Feinstein AR. Measurement of dyspnoea. Contents, interobserver correlates of two new clinical indexes. Chest 1984;85: 751-8.

13 Wolkove N, Dajozman E, Colacone A, Kreisman H. The relationship between pulmonary function and dyspnea in obstructive lung disease. Chest 1989;96:1247-51.

14 Mahler DA, Wells CK. Evaluation of clinical methods for rating dyspnea. Chest 1988;93:580-6.

15 Guyatt GH, Thompson PJ, Berman LB, Sullivan MJ, Townsend $\mathrm{M}$, Jones NL, et al. How should we measure function in patients with chronic lung disease? J Chron Dis 1985;38:517-24.

16 Wilson RC, Quirk FH, Jones PW. Correlation in asthmatic patients of magnitude estimates of dyspnoea during cycle exercise with walking distance and subjective disability but not with disturbed lung function [abstract]. Thorax but not with
$1991 ; 46: 277$.

17 Kaplan RM, Atkins CJ, Timms R. Validity of a well-being scale as an outcome measure in chronic obstructive pulmonary disease. J Chron Dis 1984;37:85-95.

18 Bergner M, Bobbitt RA, Carter WB, Gilson BS. The sickness impact profile: development and final revision of a health status measure. Med Care 1981;19:878-85.

$19 \mathrm{McD}$ owell I, Newell C. Measuring health. Oxford: Oxford University Press, 1987.

20 Walker SR, Rosser RM. Quality of life: assessment and application. Boston: MTP, 1987.

21 Streiner DL, Norman GR. Health measurement scales: a practical guide to their development and use. Oxford: Oxford University Press, 1989.

22 Read JL, Quinn RJ, Hoefer MA. Measuring overall health: an evaluation of three important approaches. J Chron Dis 1987;40(suppl):7-21S.

23 Nocturnal Oxygen Therapy Trial (NOTT) Group. Continuous or nocturnal oxygen therapy in hypoxemic chronic obstructive lung disease. Ann Intern Med 1980;133:14-20.

24 Intermittent Positive Pressure Trial Group. Intermitten positive pressure breathing therapy of chronic obstructive pulmonary disease. Ann Intern Med 1983;99:612-20.

25 Jones PW, Baveystock CM, Littlejohns P. Relationships between general health measured with the Sickness Impact Profile and respiratory symptoms, physiological measures and mood in patients with chronic airflow limitation. Am Rev Respir Dis 1989;140:1538-43.

26 Williams SJ, Bury MR. Impairment, disability and handicap in chronic respiratory illness. Soc Sci Med 1989;29: 609-16.

27 Schrier AC, Dekker FW, Kaptein AA, Dijkman JH. Quality of life in elderly patients with chronic non-specific lung disease seen in family practice. Chest 1990;90:894-9.

28 Jones PW, Baveystock CM. Impaired general health and mood in asthmatic patients in six countries [abstract]. Eur Respir J 1990;3(suppl 10):239S.
29 McSweeny J, Grant I, Heaton RK, Adams KM, Timms RM. Life quality of patients with chronic obstructive pulmonary disease. Arch Intern Med 1982;142:473-8.

30 Mahler DA, Matthay RA, Snyder PE, Wells CK, Loke J. Sustained-release theophylline reduces dyspnea in nonreversible obstructive airways disease. Am Rev Respir Dis 1985;131:22-5.

31 Harver A, Mahler DA, Daubenspeck JA. Targeted inspiratory muscle training improves respiratory muscle function and reduces dyspnea in patients with chronic function and reduces dyspnea in patients with chronic obstructive

32 Guyatt GH, Berman LB, Townsend M, Pugsley SO, Chambers LW. A measure of quality of life for clinical trials in chronic lung disease. Thorax 1987;42:773-8.

33 Guyatt GH, Townsend M, Pugsley SO, Keller JA, Short D, Taylor DW, Newhouse MT. Bronchodilators in chronic air-flow limitation. Am Rev Respir Dis 1987;135:1069-74.

34 Weir DC, Freeman W, Roberts KT, Stableforth DE, Burge PS. Comparison of a measure of quality of life in patients with cystic fibrosis and chronic airflow obstruction [abstract]. Thorax 1991;46:288P.

35 Quirk FH, Jones PW. Patients' perception of distress due to symptoms and effects of asthma on daily living and an investigation of possible influential factors. Clin $S_{c i}$ 1990;79:17-21.

36 Quirk FH, Baveystock CM, Wilson RC, Jones PW. Influence of demographic and disease related factors on the degree of distress associated with symptoms and restrictions on daily living due to asthma in six countries. Eur Respir $J$ 1991;4:167-71.

37 Jones P, Quirk F, Baveystock C, Littlejohns P. A selfcomplete measure for chronic airflow limitation-the $\mathrm{St}$ George's Respiratory Questionnaire. (Submitted.)

38 Zigmund AS, Snaith RP. The hospital anxiety and depression scale. Acta Psychiatr Scand 1983;67:361-70.

39 Jones PW, Quirk FH, Baveystock CM. The St George's Respiratory Questionnaire. Respir Med (in press)

40 Morgan AD, Peck DF, Buchanan DR, McHardy GJR. Psychological factors contributing to disproportionate disability in chronic bronchitis. $J$ Psychosom Res 1983;27:259-63.

41 Rosser R, Denford J, Heslop A, Kinston W, Macklin D, Minty $\mathrm{K}$, et al. Breathlessness and psychological morbidity in chronic bronchitis and emphysema: a study of psychotherapeutic management. Psychol Med 1983;13: psychoth.

42 Swinburn CR, Wakefield JM, Newman SP, Jones PW. Evidence of prednisolone induced mood change ("steroid euphoria") in patients with chronic obstructive airways disease. Br J Clin Pharmacol 1988;26:709-13.

43 Yellowlees PM, Ruffin RE. Psychological defenses and coping styles in patients following a life-threatening attack of asthma. Chest 1989;95:1298-303.

44 Guyatt GH, Townsend M, Keller J, Singer J, Nogradi S. Measuring functional status in chronic lung disease: conclusions from a randomized control trial. Respir Med 1989;83:293-7.

45 Fitzpatrick R. Surveys of patient satisfaction: 1-Important general considerations. BMJ 1991;302:887-9. 